THERE is a good deal of confusion at the Asilomar conference as a guide- results of the Asilomar conference and the Pasteur where a lively campaign is line, they defined the safety limits to of the experiments which were to be being waged, by means of handbills, which the experiments submitted to rumours and articles in the press, them must conform. The parent organiagainst the genetic manipulation ex- sation (CNRS, INSERM, etc.) would periments which have just started then be responsible for the effective there. control of the experiments. In this way,

The story begins a year ago; indeed when the Asilomar Conference of hygiene and safety will soon be set up February 1975 gave the go-ahead to at the Pasteur.

the genetic manipulation experiments which had been temporarily halted, French biologists who wished to do similar research were hardly taken unawares. As early as November 1974, they had asked first the CNRS and then the Délégation Générale à la Recherche Scientifique et Technique to set up an organisation to exercise some form of control over research which nobody denies could possibly be dangerous. Two committees were formed; one, with the task of ruling on the ethical problems arising from the experiments, was chaired by J. pat the so called 'low risk' experiResearch Institute for Diseases of the not been delayed in order to wait the Blood in Paris. It is made up of J. Asilomar conclusions; and it was there Monod, F. Jacob, F. Gros, R. Monier, that the 'moderate risk' experiments J. P. Ebel, Y. A. Chabert and P. were to be started which could result Slonimsky.

The other is a committee of experts comprising 15 researchers, doctors and comprising 15 researchers, doctors and were to inform the whole staff, both
biologists. With the final document of researchers and technicians, of the

\section{Asilomar and the Pasteur Institute}

from the staff of $\mathrm{La}$ Recherche

At the same time, the DGRST gave a grant of $300,000 \mathrm{~F}$ to build a laboratory to house 'the moderate risk' experiments in the Pasteur. It was there in new vaccines.

The internal meetings at the Pasteur

A NUMBER of choices and decisions must be taken this month and next to nationalise international effort on energy mesearch and development, which, otherwise, pnomises to be a farce or to duplicate what is being pursued nationally in several places. Perhaps the most significant of these moves is the one Dr Walter Marshall, Chief Scientist at Britain's Department of Energy (and Director of Harwell) claims as his personal responsibility. This is a procedure available within the 1974 Kissinger-initiated Intemational Energy Agency (IEA) for developing commercially valuable products on a consortium basis and for protecting these by licencing.

Marshall points out that it is easy to collaborate internationally on basic research and on the exchange of results, but very difficult to do work of commencial value where governments are involved, particularly the US govennment. This is first, because of the difficulty of interlocking government management, industry and government laboratories. International schemes which involve the US federal government, for example, fall foul of the American system whereby all information derived through federal participation must be freely shared with American industry. Some months ago Marshall successfully argued that commercial undertakings should be in-

\section{Marshalling our power \\ from Angela Croome}

cluded in the agency's programme and that industrial protection was needed for non-American industrial participants.

Only 10 days ago a compromise agreement was reached after several midnight sessions and this has been recommended to the British government for endorsement. It provides a means of setting up industrial consortia with defined objectives and the production of industrial 'products' for licencing. Member countries of the IEA can opt out of any of them. When the product has emerged the countries which had not chosen to join in that particular project would have either to buy a licence to manufacture or make a down payment later.

Nine research themes for the IEA have been chosen so far, including coal, energy from municipal and industrial waste, radioactive waste management, fusion use of waste heat, energy conservation, solar energy, hydrogen conversion and nuclear safety. The concept of the 'lead country' is, in the main, being adopted in the organisation of the work, existing investment and effont being the leadership criteria. carried out.

Nobody expected the explosion which followed these meetings, the first of which had taken place in April. One group of research workers and technicians undertook to fight both the decision to place the special laboratory within the department of molecular biology and also the experiments themselves. An atmosphere of panic overran the Pasteur. Institute biologists and others formed themselves into a 'biological-information group' and recently they have published a manifesto demanding the suspension of experiments and a public meeting where the advantages and disadvantages of the experiments could be debated.

The dissenting movement is very large. It has to be seen within the political and philosophical framework which brings into question genetic manipulation as well as other biological research, virology, genetics etc., where the dangers must be weighed against expected benefits. The movement contests the present reliance on the scientific expert. It questions the way in which science is run, both at the Pasteur, and in general. And finally it poses the problem for whom is science done, scientist or people?
Of the programmes already well developed, for example, fusion work is likely to be led from within the EEC but application is still too far off for a commercial consontium to be needed.

Britain may well take the leadership on coal utilisation research and the fluidised bed development has now reached the consontium stage. Britain has also put money into its own radioactive waste programme so would be expected to participate in the agency's.

Many of the IEA themes are duplicarted under the EEC's joint programme, but the organisation and decision-making structure of the latter is very different. The requirement that all EEC decisions have to be unanimous results in decisions being political rather than scientifically based. Whatever may the point of view of the advisers of other EEC countries, Marshall expects to get better value out of the IEA. The budget for Europe's Joint Research Centre is still under review, though expected to be settled this month, and there is every likelihood that most of the proposed programme will be adopted and for this there are obligatory contributions. For EEC members such as Britain, therefore, it seems logical for the IEA to subsume many of the same programmes. By routeing participation through the EEC, member countries should avoid paying twice. 